\title{
Metacognitive Skills with Mathematical Problem - Solving of Secondary School Students in Vietnam - A Case Study
}

\author{
Nguyen Thi Huong Lan \\ Department of Fundamental Science, Tan Trao University, Tuyen Quang Province, Vietnam \\ Received September 15, 2020; Revised November 3, 2020; Accepted November 19, 2020
}

\section{Cite This Paper in the following Citation Styles}

(a): [1] Nguyen Thi Huong Lan, "Metacognitive Skills with Mathematical Problem - Solving of Secondary School Students in Vietnam - A Case Study," Universal Journal of Educational Research, Vol. 8, No. 12A, pp. 7461 - 7478, 2020. DOI: 10.13189/ujer.2020.082530.

(b): Nguyen Thi Huong Lan (2020). Metacognitive Skills with Mathematical Problem - Solving of Secondary School Students in Vietnam - A Case Study. Universal Journal of Educational Research, 8(12A), 7461 - 7478. DOI: 10.13189/ujer.2020.082530.

Copyright $\odot 2020$ by authors, all rights reserved. Authors agree that this article remains permanently open access under the terms of the Creative Commons Attribution License 4.0 International License

\begin{abstract}
Mathematics education in the 21st century is facing new problems in the real world, cultivating creative thinking skills and effective learning. In an effort to innovate teaching and learning methods to prepare for future generations with the demands of the new era, many educators have discovered the value of metacognition. Objective of the research: to understand the impact of metacognitive activities on the ability of solving math problems of students at secondary schools in Vietnam based on that, the author offers ways to practice the metacognitive skills in order to foster the problem-solving competence in math for students at this level. Research Methods: This research uses survey, descriptive studies. The tools used are structured questionnaires, learning cards, and practical and math problems. The subjects of this study are 18 students at grade 9. Research results: Although metacognition and metacognitive skills are terms that rarely appear in the awareness of junior high school students, but metacognitive skills still accompany students at this level in the process of learning math; Junior high school students still regularly practice three groups of metacognitive skills: orientation and planning skills, tracking and adjustment skills, and assessment skills in their math learning process. Through the observation process, students show skills in problem solving process. Since then, the student's math results have been improved.
\end{abstract}

Keywords Metacognitive Skills, High- Order
Thingking Skills, Math Problems, Mathematic Education Methods

\section{Introduction}

Math is always one of the difficult subjects for students [17]. Metacognitive processes focus on students' ability to supervise and adjust their own cognitive processes in problem solving [2], [26]. Many scholars have argued that the emphasis on awareness without focusing on metacognitive thinking makes an inadequate problem-solving effort [14], [15], [33], [34], [35]. Some experts specify that metacognition is a person's knowledge of cognitive processes and a person's perception of a mathematical problem related to the planning, monitoring and evaluation process of problem solutions [12]. In metacognition, the ability to think about thought is central to this process because it relates to awareness of the cognitive process and its ability to control it. Metacognition has two main components: knowledge of cognition and cognitive control [3]. According to Flavell [12], metacognition is an system of information, experience, goals and strategies. Metacognition, which means thinking about thinking, generally includes many skills related to thinking and learning, which are critical thinking, problem solving and decision making. The 
person, who has more developed metacognitive skills, is also a better problem solver, decision maker and critical thinker than others. The problem is to know what to do. Actual problem-solving processes include processes and skills. Solving the problem is to find a solution to escape difficulties other than reaching solutions. Math teachers need to make every effort to help students succeed, try to find the best ways to teach, get students involved in the learning process.

Following RW Hollingworth, C McLoughlin metacognitive term refers to learners' knowledge of their cognitive processes and their ability to control and monitor them as a function of feedback that learners receive through learning outcomes [24], [25]. Therefore, the two essential components of metacognition include knowledge and control. Knowledge in metacognition is understanding what learners understand and believe in an issue or task, and the judgments they make in allocating cognitive resources as a result of that knowledge [13], [7]. Metacognitive controler controls the approaches and strategies that learners devise to achieve specific learning goals and the extent to which learners organize, track and modify those activities to ensure that learning is effective.

According to Kuhn, D. [19], Metacognition becomes clearer, stronger and more effective as it operates increasingly under the conscious control of each individual. Raising (a) metacognitive awareness about what people believe and how people know it and (b) controlling strategies in adopting new information processing strategies are important objectives of development and education.

In the field of mathematics, problem solving is a common process. This paper presents the impact of students' metacognitive skills on success in solving mathematical problems. Research focuses on the study of students' cognitive and metacognitive skills.

\section{Theoretical Framework}

\subsection{Metacognition in Math Education}

In the 80 s of the 20th century, educators studying problem solving in mathematics became interested in the concept of metacognition. Some of the more frequently asked questions by math scientists and educators are "Can problem solving be taught?", "How does understanding play a role in problem solving?", "How does metacognitive behavior play a role in problem solving?" [22]. A number of student problem-solving studies in the context of math education have proven that students do poorly in academic tasks that require more than one math step and the math teacher seems to have difficulties in planning and implementing lessons to form problem-solving skills for students [18]. So the concept of metacognition appears to be a useful tool to promote learners' ability to solve problems. For example, Lester's study (1982) focused on the role of metacognition in student problem-solving. Lester [22] pointed out that students' understanding of cognitive activities before, during and after problem solving along with the ability to maintain executive activities such as monitoring and self-adjusting photos have important influence to the successful solving of math problems. Therefore, metacognitive activities involve at least two of the five components necessary for successful problem solving. Along with mathematical knowledge and experience, the ability to create instrumental skills such as separating relevant information from irrelevant information and using representations related to the remaining components of the problem are important to successfully solve the problem. The research by Verschaffel [28] also shows that metacognition plays a particularly important role in solving mathematical problems. He argues that metacognition, in the predictive sense, is a tool in the early stages of solving mathematical problems when problem solvers try to build an appropriate model of the problem. Verschaffel [28] also emphasizes the role of metacognition, in the sense of evaluation, in the final stages of problem solving when the results of the calculation process need to be checked.

Brophy [6] also emphasizes the role of metacognition in the process of teaching metacognitive skills. According to him, teachers need to apply cognitive and metacognitive activities to provide learners with knowledge about identifying appropriate skills, knowledge about skill using and knowledge of conditions (when how and why) to use those skills. Silver [27] also emphasizes the importance of problem-solving by problem solvers in the process of solving math problems, for example when choosing between cognitive strategies to support problem-solving solutions. The process of making decisions is not only metacognitive but also influenced by individual beliefs. Accordingly, in the context of solving mathematical problems, beliefs about learning and solving problems in general and beliefs in solving mathematical problems, in particular, can be considered as an important guide in coding and accessing mathematical materials.

Sharing the same view with the researchers, Garofalo and Lester [14] emphasize the importance of metacognition for analysis and understanding of mathematical representation. The researchers argue that analyzing a student's pure cognitive perception of mathematical expression is not enough. When referring to the difference between knowledge and cognitive adjustment, these researchers believe that not only are modifiable metacognitive behaviors, but also categories of metacognitive knowledge perceptions, tasks and strategies are important in learners' mathematical representations. According to [14], personal knowledge in the field of mathematics includes an individual's assessment of their own abilities and limitations on mathematics in general and mathematical topics in particular. Task knowledge in the field of mathematics includes personal beliefs in the topics of mathematics as well as beliefs in the nature of 
mathematical tasks. Task knowledge includes personal awareness of aspects of a mathematical task such as content, context, structure, difficulty, solution ... Strategic knowledge related to awareness of a person on strategies to assist in understanding problem statement, organizing data information, planning to find solutions, executing plans and checking results. By the 1990s and early 21 st century, a number of studies focused on understanding the importance of metacognitive skills in the process of solving mathematical problems. These studies emphasize procedural metacognition knowledge such as planning, monitoring and adjustment [10].

Therefore, conducting research in this direction to understand the students' metacognitive skills in the process of solving mathematical problems is really necessary. In particular, understanding the impact of metacognitive skills on mathematics problem solving ability of junior high school students plays an important role in the orientation of teaching methods to develop solving problems competencies in particular and mathematics competencies of junior high school students in particular.

\subsection{Metacognition and Math Problem Solving}

The process of mathematics of individual activities from learning to work is taking place vigorously in the early years of the 21 st century, which requires learners to learn math more and more differently than the school math [20]. Today the math topics taught in schools not only focus on computational skills but also on developing the ability to solve problems for learners [32]. According to some educators, problem solving plays an important role in the math program because it is able to support the process of building new knowledge and help learners solve problems that arise in math or in life. However, some studies also show that the ability to solve problems of learners is limited. The limitation of students' ability to solve problems is not because of the lack of mathematical knowledge but because of the limitation of the ability to analyze problems to fully understand it, the lack of full appreciation of the information in order to produce an effective problem-solving plan. Little attention has been paid to evaluating the feasibility of a given plan and the validity of the results [20]. Victor [30] points out that students fail to solve problems because they have not paid attention to organizing mathematical operations, choosing effective options, monitoring and adjusting the conducting process. It is the limitation of metacognitive skills that affects the success of learners in problem solving

Metacognition helps learners identify the presence of a problem that needs to be solved, to distinguish exactly what the problem is and to understand how to achieve a problem solving solution. For the successful solution of any complex problem-solving process, a series of metacognitive processes are needed such as planning adjustment, monitoring, inspection, revision and evaluation, especially the use of mathematical representations and evaluation of the effectiveness of problem-solving options. As metacognition plays an important role in problem solving, there is an increasing number of studies investigating the role of metacognition in problem solving under various aspects. Kuzle [20] pointed out a number of cases where metacognition is mentioned in problem-solving studies such as metacognitive processes in student problem-solving activities, the role of metacognition in problem solving, the role of non-cognitive factors such as beliefs, values in problem solving, the influence of metacognitive-oriented teaching on solving processes problem solving. Kuzle [20] has concluded that although metacognitive practitioners have been studied and its influence on problem solving has been initially shown, studies on metacognition in the process of problem-solving is necessary to conduct to identify the influence of metacognition in the problem-solving process of learners.

Researchers have shown metacognitive behavior when studying problem-solving activities or studying the phases of problem-solving. Lawson and Chinnappan [23] have pointed out five steps when dealing with situations in solving geometric problems which are recognizing given information, managing problems, building new information, self-assessment and correct the errors. Based on a comparison of the performance of students with high academic achievement and those with low academic achievement, the two researchers concluded that the ability to gain more knowledge and start by handling are critical to success in problem solving. Lester et al. [21] studied the role of metacognition in problem solving behaviors of 7 th grade students. The researchers used a theoretical framework of elements to consider the different actions that students take when working on a mathematical task: orientation (strategic behavior to evaluate and understand the problem), organization (activity planning and action selection), implementation (adjust behavior in accordance with the plan) and reflection (evaluate the decision made and the outcome of the implementation plan). The results show that the orientation phase has the greatest influence on the outcome of the learners' problem solving process.

Wilson and Clarke [29] developed a multi-method technique to understand individual metacognition. The three metacognitive structures that have been tested are metacognitive, metacognitive evaluation, and metacognitive tuning. Although Wilson and Clarke [29] can explain learners' metacognitive behaviors through the cognitive-evaluation-adjustment cycle, the two researchers have not yet taken measures to develop the problem-solving abilities of students. Kuzle [20] used dynamic geometry technology, specifically Geometer's Sketchpad's dynamic geometry software to track individual metacognitive behaviors in solving geometry problems in three aspects of metacognition proposed by [29] and access to interactive tools of Artigue [31]. Kuzle [20] used the model of problem-solving stages proposed by Schoenfeld 
(1981) to recognize the rules of metacognitive processes in dynamic geometry. Kuzle [20] pointed out that during the reading, comprehension and analysis phase, learners are actively involved in the monitoring process by activities such as mapping and locating potential resources and approaches to help make effective decisions. During the discovery, implementation, evaluation, and reflection stage, learners make decisions to evaluate and review knowledge and options, formulate hypotheses and test hypotheses, monitor progress, assess the effectiveness of the operation as well as the correctness of the problem-solving plan. Kuzle [20] concludes that learners will achieve effective problem-solving solutions when their own perceptions of how to solve problems are driven by their own metacognitive activities. Although problem-solving researchers have been trying to understand metacognition to get a proper view of the nature of this activity over the years. Metacognition is still a mysterious structure today when educators want to decipher its role in decision-making in the learners' problem-solving process.

\subsection{Metacognitive Model}

\section{Flavell's metacognitive model}

Flavell [11] introduced components of metacognition and highlighted their characteristics.

- Metacognitive knowledge;

- Metacognitive experiences;

- Cognitive goals;

- Activities and strategies.

The ability of individuals to adjust cognitive outcomes depends on the interaction between cognitive strategy, cognitive experience, metacognitive knowledge and metacognitive experience.

The above elements have their own contents, functions and tasks but have an interaction with each other, supporting each other towards the common goal of promoting teaching effectiveness. The model of Flavell (1979) (Figure 1) enhances the thinking process, the connection of knowledge as well as the understanding of learners when performing learning tasks. This model promotes the creative subjectivity of learners, from then they have the right to make decisions and take responsibility for their own decisions. Flavell [11] provided basic understanding of metacognition and the components of a metacognitive model. This is an important theoretical basis for later psychologists and educators to develop a more comprehensive metacognitive theory.

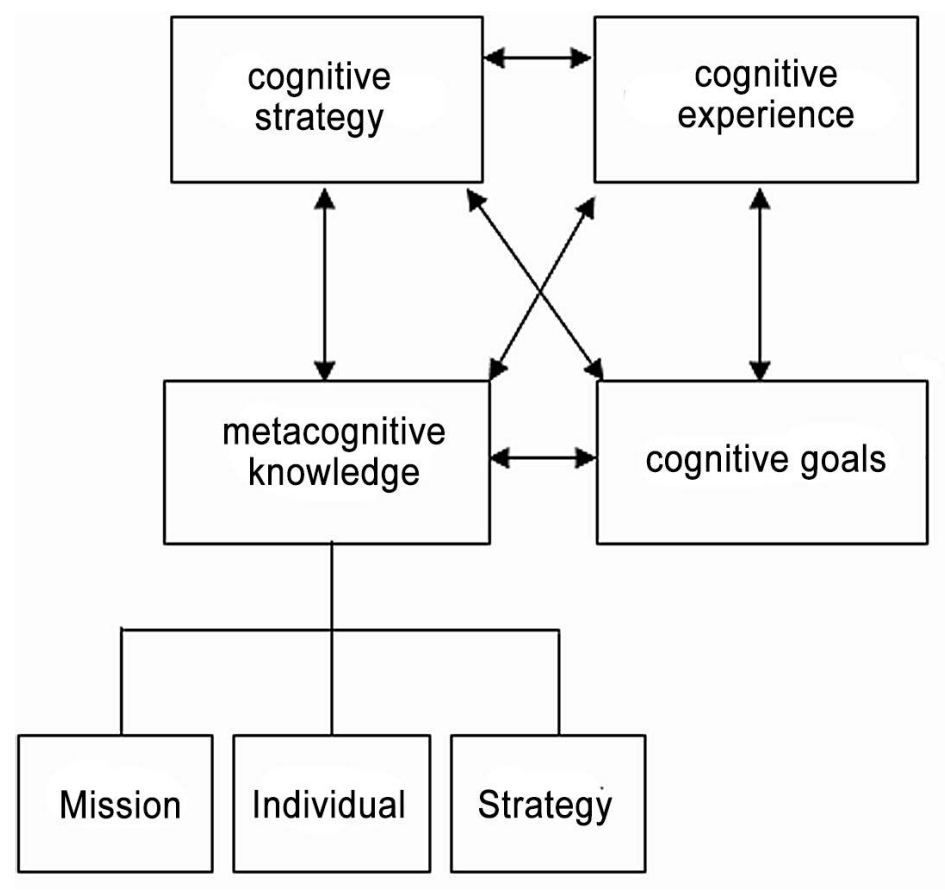

Figure 1. Metacognitive model of Flavell (1979) 


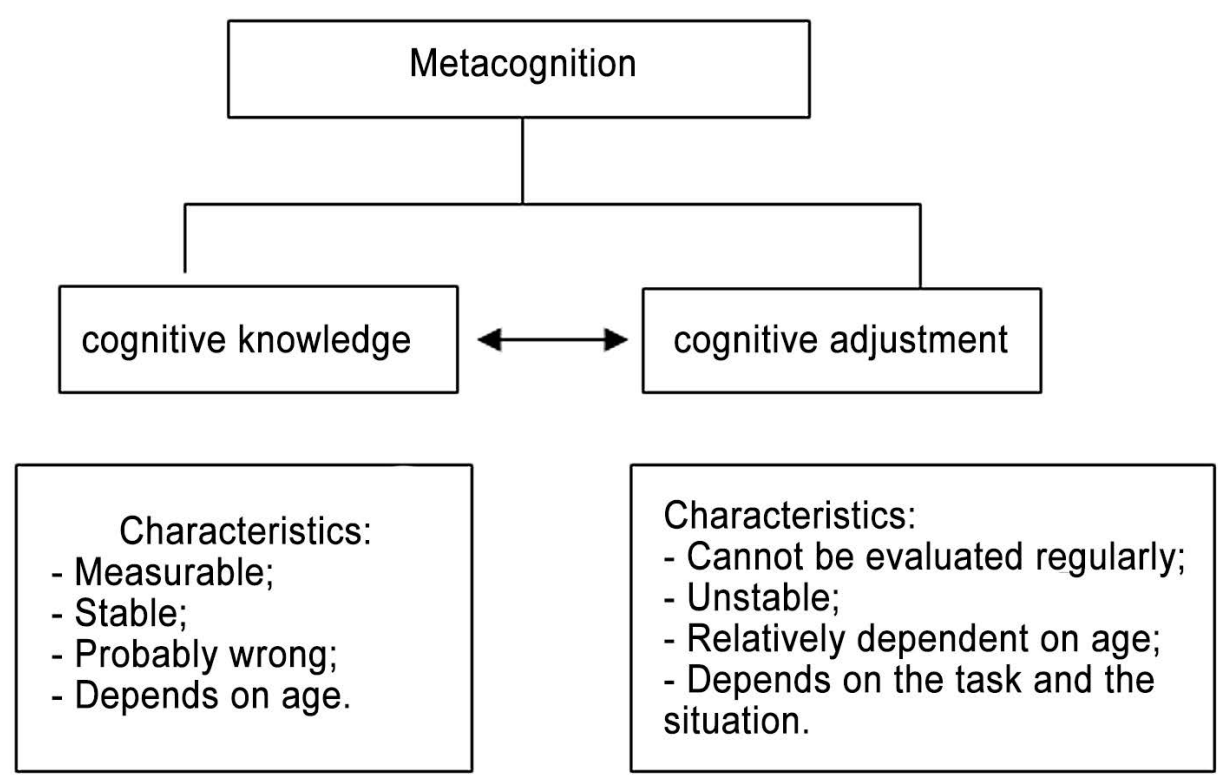

Figure 2. Metacognitive model of Brown

\section{Brown's metacognitive model}

Ann Leslie Brown (1943-1999) is an American educational psychologist. Her research focuses on human memory and memory development strategies. Brown [5] divided metacognition into two components: cognitive knowledge (conscious reflection of one's own abilities and cognitive activities) and cognitive adjustment (self-regulation in task solving process). These two components have their own characteristics but have a reciprocal relationship, promoting each other and promoting learners' cognitive activities (Figure 2).

In the model above (Figure 2), cognitive knowledge supplies answer for what the individual knows. Cognitive knowledge includes what individuals accumulate through interaction with the environment and society. This type of knowledge is usually stable, measurable, probably wrong and depends on age. Brown has classified metacognitive knowledge including informational knowledge (knowing what); process knowledge (know how) and conditional knowledge (know when and why).

Cognitive adjustment includes activities used to monitor and adjust learning. This process includes planning before implementation, monitoring that process and checking results. This adjustment has characteristics such as instability, not depending on age, but mainly on tasks and situations. The metacognitive model proposed by Brown points out and analyzes the characteristics of the two components of metacognitive theory. These two components have a mutual interaction. The performance of a new task is based on the accumulated knowledge and perceived knowledge that is the basis for the individual to adjust the process when performing the next cognitive task.

\section{The metacognitive model of Tobias and Everson}

According to Tobias and Everson (Figure 3), metacognition is a combination of factors such as skills, knowledge (cognitive understanding), monitoring learners' cognitive processes and controlling them as following model:

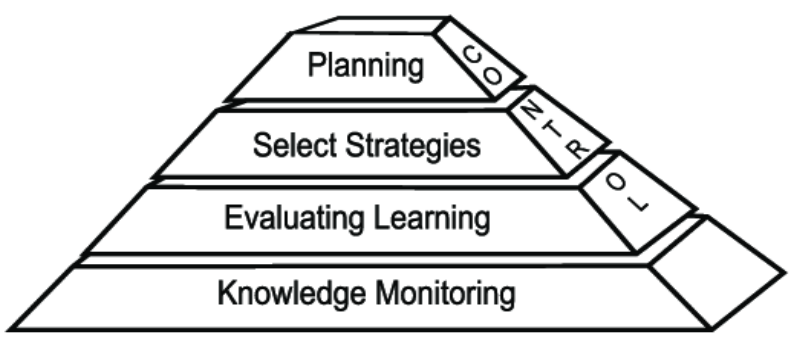

Figure 3. Hierarchical model of metacognitive processes (Tobias and Everson, 2002)

- Planning: The student's first task in metacognitive activities is to plan including identifying learning goals, learning time, and estimating results;

- Choosing strategy: After planning, learners need to choose appropriate strategies and methods to perform that learning task;

- Assessing learning: When the learning strategy is completed, learners need to evaluate their learning including assessing the process and evaluating the results achieved in comparison to the set goals. Assessment is an important activity to help students have a basis for adjusting their learning.

- Tracking knowledge: Track your level of understanding at each different stage, monitor the effectiveness of the methods used to choose the optimal method. The goal of tracking knowledge is to 
know what you know and what you don't know. If students do not know exactly what they know and what they do not know, it is difficult to engage in metacognitive activities such as assessing their own learning, planning, or controlling that learning process. On the other hand, students with metacognitive skills will know their own knowledge; they will know what is the core knowledge, which they need to acquire. From there, they can use their time effectively, find ways to carry out their tasks, make learning more effective. Knowledge tracking is therefore viewed as a fundamental activity, as a basis for conducting other activities.

- Controlling: What dominates the monitoring process is control. The control is to coordinate the learning process or perform the tasks of the learner, then the learner can make decisions to continue or stop when a certain direction is no longer consistent with the goal.

The three metacognitive models above describe in detail the components of metacognitive theory. Over time, the elements of metacognitive theory have become more and more explicitly described by researchers. Besides the three metacognitive models, Beyer [4] suggested that metacognition consists of three components: planning; tracking and evaluating. Anderson [1] divided metacognition into several components: preparing and planning for learning; Selecting and using strategies and learning. Other researchers agree that metacognition includes metacognitive knowledge, control and regulation.

It can be seen that the theory of metacognition is constantly being supplemented, completed and closer to educational issues so that learners can flexibly apply to study and work in many different situations. From there, learners form and develop the skills needed for academic work: planning and selecting methods, evaluation, monitoring and control.

\subsection{Metacognitive Skills in the Process of Solving Mathematical Problems}

According to Gregory Schraw, David Moshma [16], metacognitive theories are broadly defined as system frameworks used to explain and directly perceive metacognitive knowledge and adjustment skills. To describe the metacognitive aspects of learners in the process of solving mathematical problems, Garofalo and Lester [14] have proposed four metacognitive activities related to solving any mathematical task, which are orientation, organization, implementation and evaluation. Garofalo and Lester [14] have shown that making metacognitive decisions in problem-solving processes depends on the problem that learners are solving. However, they emphasized that learners always conduct cognitive and metacognitive processes at the same time when solving problems. According to [14] cognition is related to problem solving while metacognition is related to the selection, planning, and monitoring of problem-solving processes. Cognitive behaviors can be expressed verbally or non-verbally but focus on information processing. In the meantime, metacognition is expressed under statements related to the problem or problem-solving process. Campione, Brown and Connell [8] emphasize that successful problem solvers often have good ways to handle novel problems. They monitor and adjust these problem-solving options effectively while weaker students pay less attention to them or use them flexibly.

According to Davidson and Sternberg [9], metacognition allows learners to identify and work strategically with three aspects of a problem. Specifically, metacognitive skills help learners: (a) code the nature of the problem and formulate a model or represent the elements of the problem strategically; (b) choose the appropriate plan and options to achieve the goal; and (c) identify and overcome problems encountered when solving the problem. Knowledge of problem-solving processes in general and thinking processes will help students become better problem solvers. Therefore, metacognition plays an important role, which is useful in developing problem-solving skills.

Based on the theoretical framework of metacognition in the problem solving process of learners, Artzt and Armor Thomas [2] have proposed theoretical framework for metacognition in solving mathematical problems of small groups including 8 steps with the expressions described in Table 1 .

In this study, I apply the theoretical framework proposed by Artzt and Armor- Thomas (1992) [2]. 
Table 1. Theoretical framework for metacognition in problem solving (Artzt and Armor - Thomas, 1992)

\begin{tabular}{|c|c|c|}
\hline Step & Description & Expression \\
\hline $\begin{array}{c}\text { 1: Identify problems } \\
\text { (cognition) }\end{array}$ & Students read the problem & $\begin{array}{l}\text { Students read the problem or listen to someone else reading it } \\
\text { Students can either read the problem silently or read it aloud. }\end{array}$ \\
\hline $\begin{array}{l}\text { 2: Understand } \\
\text { problems } \\
\text { (metacognition) }\end{array}$ & $\begin{array}{l}\text { Students consider what knowledge is appropriate } \\
\text { for the problem. That knowledge includes } \\
\text { language awareness, semantics and diagrams that } \\
\text { are in the problem in a way that the problem is } \\
\text { expressed in another format. }\end{array}$ & $\begin{array}{l}\text { Students may exhibit some of the following behaviors: } \\
\text { a) Express the problem in their own words; } \\
\text { b) Request clarification of the meaning; } \\
\text { c) Represent the problem by writing basic data or by making a } \\
\text { table or diagram; } \\
\text { d) Remind themselves or others of the problem requirements; } \\
\text { e) Recall if they have done a similar problem before; } \\
\text { f) Discuss the presence or absence of important information. }\end{array}$ \\
\hline $\begin{array}{c}\text { 3: Analyze } \\
\text { problems } \\
\text { (metacognition) }\end{array}$ & $\begin{array}{l}\text { Students analyze problems into fundamentals and } \\
\text { examine explicit or hidden relationships between } \\
\text { given and goals that need to be addressed. }\end{array}$ & $\begin{array}{l}\text { Students endeavor to simplify or transform the problem, and } \\
\text { attempt to select the appropriate transformative approach that } \\
\text { is promising under those conditions. }\end{array}$ \\
\hline $\begin{array}{l}\text { 4: Planning } \\
\text { (metacognition) }\end{array}$ & $\begin{array}{l}\text { Students choose problem-solving steps and strategies } \\
\text { to corporate those steps so they are likely to lead to } \\
\text { solutions if implemented. In addition, students can } \\
\text { assess the status of the solution and may decide to } \\
\text { change it if necessary. }\end{array}$ & $\begin{array}{l}\text { Students describe the intended approach used to solve the } \\
\text { problem. This may be in the form of steps to be taken or } \\
\text { strategies used. }\end{array}$ \\
\hline \multicolumn{3}{|l|}{$\begin{array}{l}\text { 5: Exploration } \\
\text { (cognition and } \\
\text { metacognition) }\end{array}$} \\
\hline $\begin{array}{l}\text { 5a: Exploration } \\
\quad \text { (cognition) }\end{array}$ & $\begin{array}{l}\text { Students implement a trial-and-error strategy to solve } \\
\text { problems that shorten the gap between what is given } \\
\text { and what the goal is. }\end{array}$ & $\begin{array}{l}\text { Students perform a series of random false tests, make } \\
\text { predictions, and test them }\end{array}$ \\
\hline $\begin{array}{l}\text { 5b: Exploration } \\
\text { (metacognition) }\end{array}$ & $\begin{array}{l}\text { Students monitor their progress or the actions of their } \\
\text { classmates to decide whether to continue or end work } \\
\text { through such manipulations. Based on the results of } \\
\text { previous actions the learner will decide whether to } \\
\text { continue the discovery process. }\end{array}$ & $\begin{array}{l}\text { a) Students leave the problem to ask themselves or others } \\
\text { what has been done during the exploration process. } \\
\text { b) Students give suggestions to other students what to try next } \\
\text { in the exploration process. } \\
\text { c) Students assess the status of exploration. }\end{array}$ \\
\hline $\begin{array}{l}\text { 6: Implementation } \\
\text { (cognition and } \\
\text { metacognition) } \\
\end{array}$ & & \\
\hline
\end{tabular}
understanding, analyzing decisions and making

6a: Implementation judgments about their plans.

(cognition) Unlike exploration, students' actions are characterized by the quality of the system and the prudence in transforming the given into goals that need to be achieved.

Students participate in metacognitive processes as in exploration process (metacognition) and solve problems according to the course of their actions. 6b: Implementation However, unlike the exploration process, (metacognition) metacognitive decisions are made with the purpose of examining or changing previously reviewed decisions. Moreover, students can transfer resources to solve their problems, assigning time to solve problems.
Students perform a series of sequential and coherent calculations. There should be the evidence of an orderly process.
During the process, students may temporarily withdraw from work, consider what has been done and what they can achieve.

\begin{tabular}{|c|c|c|}
\hline $\begin{array}{l}\text { 7: Confirmation } \\
\text { (cognition and } \\
\text { metacognition) }\end{array}$ & & \\
\hline $\begin{array}{l}\text { 7a: Confirmation } \\
\text { (cognition) }\end{array}$ & $\begin{array}{l}\text { Students assess the results of work by examining } \\
\text { computational activities. }\end{array}$ & $\begin{array}{l}\text { Students do the math operations again to check if they have } \\
\text { been done correctly. }\end{array}$ \\
\hline $\begin{array}{l}\text { 7b: Confirmation } \\
\text { (metacognition) }\end{array}$ & $\begin{array}{l}\text { Students evaluate the answers by commenting on } \\
\text { whether the results reflect understanding, analysis, } \\
\text { or planning to solve the problem. Students need to } \\
\text { detect inconsistencies in such reconciliation; } \\
\text { students make new decisions to correct detected } \\
\text { conflicts. The ability to comment on the basis of } \\
\text { information evaluation is another indicator of } \\
\text { self-regulation. }\end{array}$ & $\begin{array}{l}\text { Once students have reached a solution or a part of answer, } \\
\text { they can look back on their work in several ways: } \\
\text { a) Students examine the problem-solving process to see if it } \\
\text { makes sense. } \\
\text { b) Students check if the solution satisfies the conditions of the } \\
\text { problems } \\
\text { c) Students explain to the group how the solution has been } \\
\text { achieved. }\end{array}$ \\
\hline $\begin{array}{l}\text { 8: Observe \& Listen } \\
\text { (not categorized) }\end{array}$ & $\begin{array}{l}\text { This category concerns students who work with } \\
\text { others. The students who are attentive to the ideas and } \\
\text { work of others. }\end{array}$ & $\begin{array}{l}\text { Students listen and observe when group members speak or } \\
\text { write. }\end{array}$ \\
\hline
\end{tabular}




\section{Research Methods}

\subsection{Objectives}

The main focus of this research is to build a theoretical model of metacognition in mathematics for solving the problem of context. The object of the study is students of Phan Thiet Secondary School, Tuyen Quang Province.

\subsection{Research Questions}

This study aims to answer the following questions:

1. What thinking skills do students use when they rethink problem solving?

2. What is the reality of applying metacognition to solving mathematical problems of students in Phan Thiet Secondary School, Tuyen Quang province?

\subsection{Research Tools}

Research using survey, descriptive studies. The tool used is structured questionnaire. The students in this study are 18 students at 9th grade of Phan Thiet Secondary School, Tuyen Quang province. The class consists of 04 boys and 14 girls, divided into two groups: 9A group is considered a capable group. and the 9B group is considered a lower ability group (according to teacher's evaluation)

The tools of this study include a survey and 2 situations in the junior high school curriculum. The content of the survey includes 20 questions about using students' metacognitive skills in the process of solving math problems.

\section{Problem 1. Compare the area of two gardens}

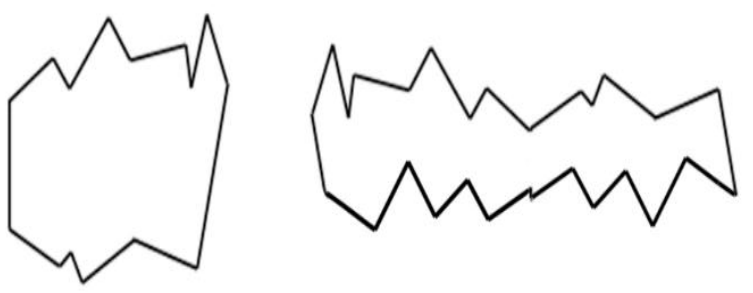

Figure 4. Area comparison

Mr. An needs to buy one of the two gardens as shown (fig. 4). If you were Mr. An, which garden would you choose? Explain why you chose that garden. If you think that there is not enough information to give an suggestion to $\mathrm{Mr}$. An, what information do you need and how will you use it to solve this problem?

This is a problematic situation for most students in general and junior high school in particular because students often have problems in comparing the area of regular shapes such as triangles, rectangles, shapes. square or circle. With the problem of comparing the area of regular geometric shapes, the learner will orient to use the learned geometry knowledge to create accurate conclusions for the given problem such as using formulas, overlapping, drawing the complement of the shapes, etc. However, in this situation, it is difficult for students to access in the usual ways that have been learned and practiced before. To compare the areas of these two shapes, students can use some area estimation methods. Students can draw extra lines to divide the shapes A and B into small shapes as follows (fig. 5), thereby showing the area of the pieces in two approximately shapes to conclude the area of A approximating the area of $\mathrm{B}$ :
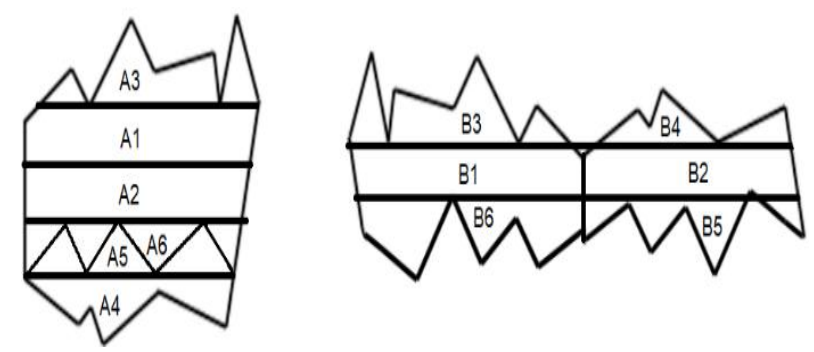

Figure 5. Divide the area of two gardens

Therefore, if you are only interested in the area of two gardens, then you can choose any of them. However, A is wider, the land is more square, so depending on the purpose of use, the buyer will consider which land to choose.

Problem 6: Estimate area (fig. 6): Today, while rearranging the family's bookshelf, Hong stumbled across a map of continents with accompanying proportions. Please help Hong to measure (as accurately as possible) the area of Antarctica. The results may be acceptable if the Antarctic continental area is in the range of $12,000,000 \mathrm{~km} 2$ to $18,000,000 \mathrm{~km}^{2}$. 


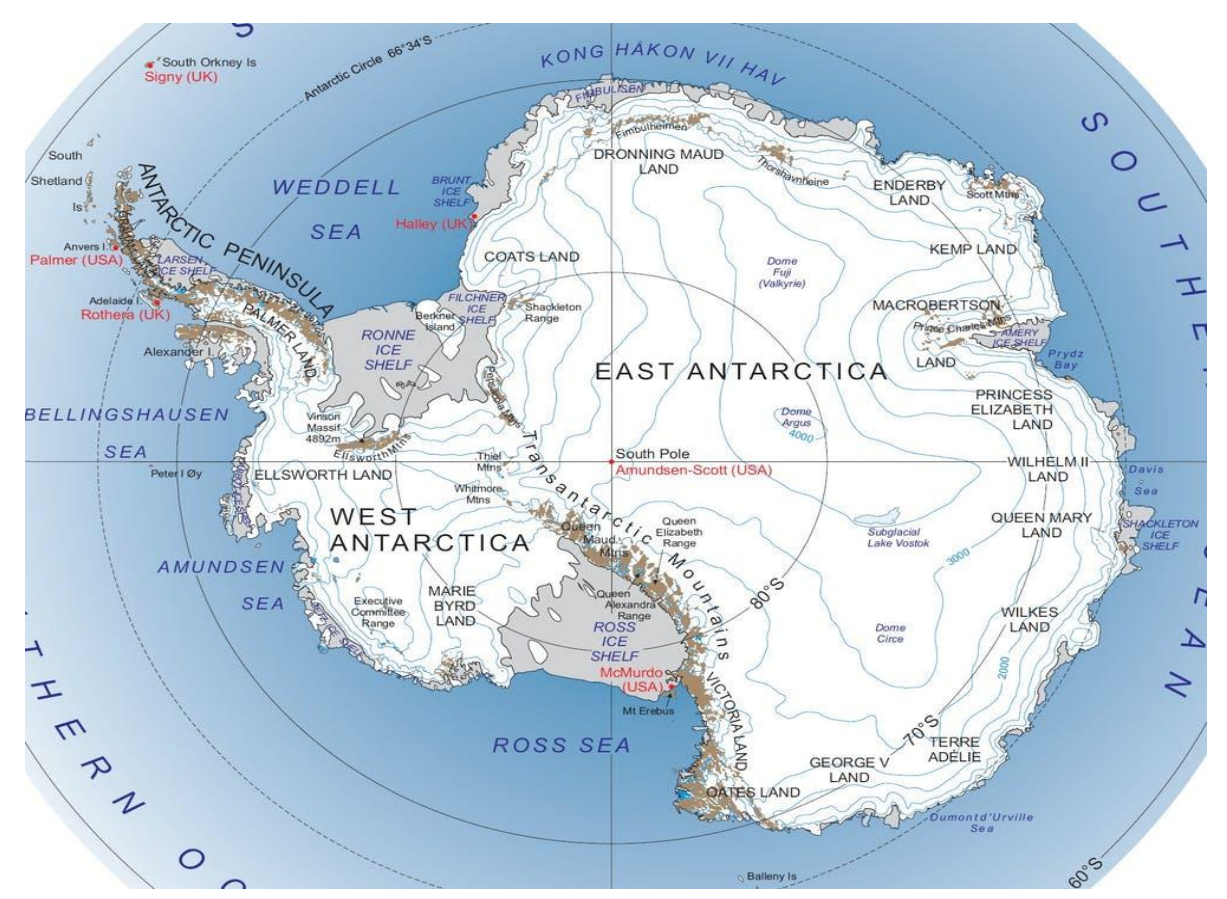

Figure 6. Estimate the area of Antarctica-Group1

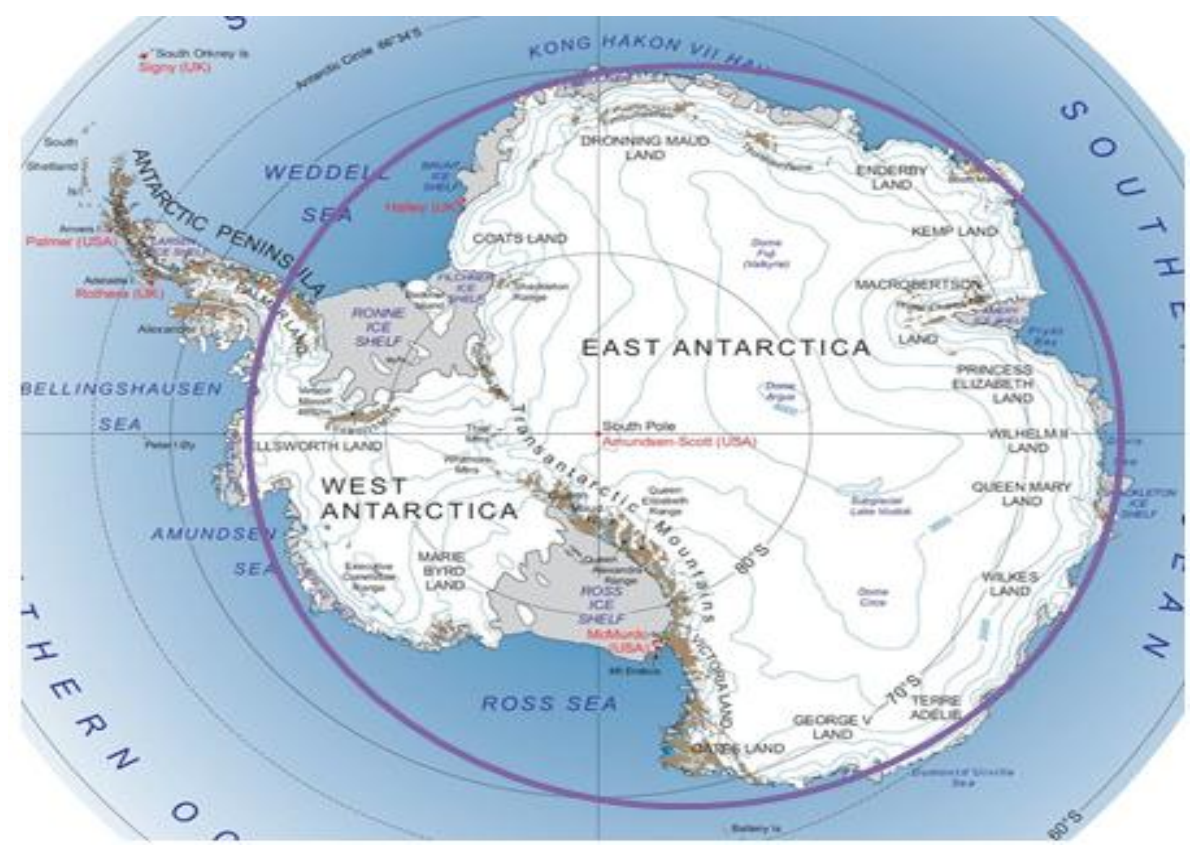

Figure 7. Estimate the area of Antarctica by a circle

In order to solve this problem, learners can find ways to construct shapes approximately the area of the Antarctic area so that the area of those shapes can be calculated using mathematical formulas. The first way is that students use compass to draw a circle around the continent, then calculate the area of the circle and estimate the area of the Antarctic continent. This result is acceptable because the continental area will be within the permitted range (fig. 7).

Students can use the Quadrangle surrounding the Antarctic continent to approximate the area of the
Quadrangle with the area of the Antarctic continent as shown below (fig. 8).

From calculating the area of the quadrilateral, eventually converting into actual results students can get the area of the Antarctic continent. This result is acceptable because the continental area will be within the permitted range.

Learners can use triangles and quadrangles outside the Antarctic continent to estimate the area of the continent. The area of the continent will be approximately equal to the area of the polygon given by fig. 9 . 


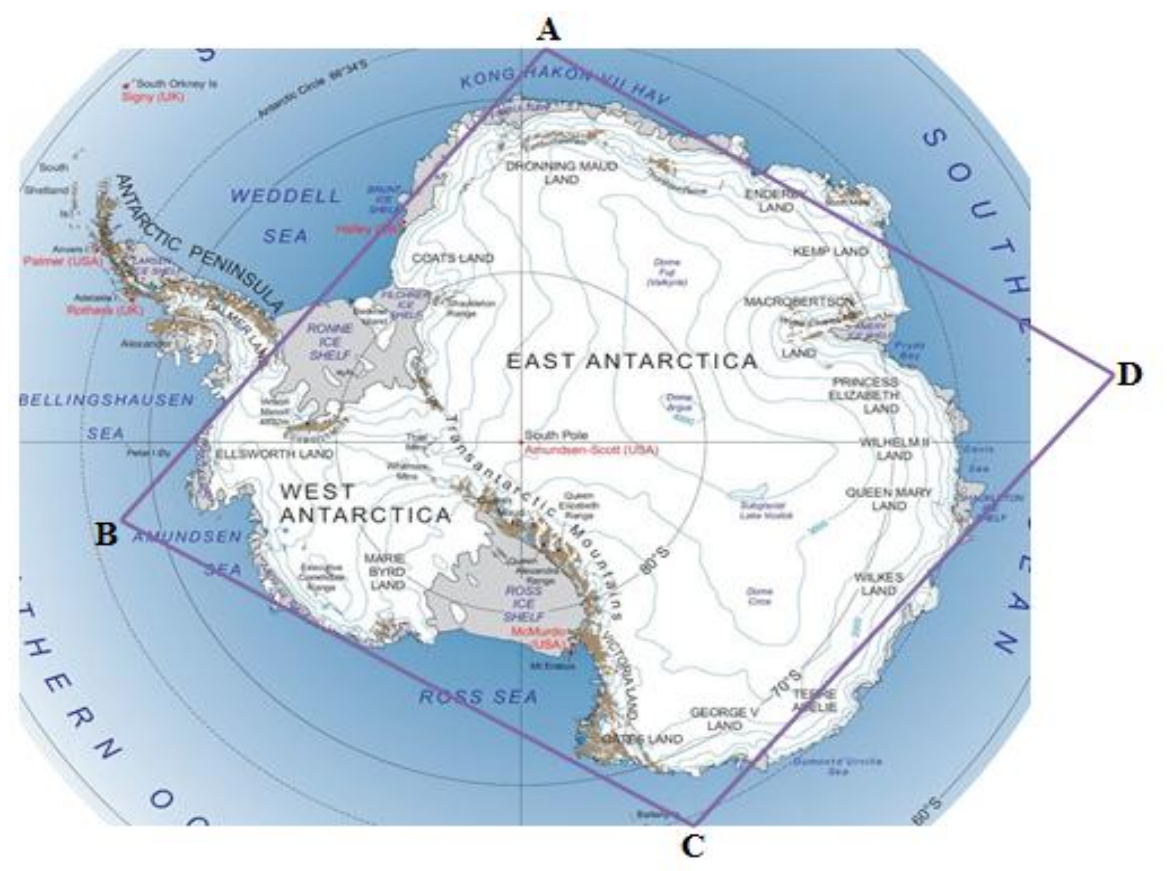

Figure 8. Estimate the area of Antarctica by polygons

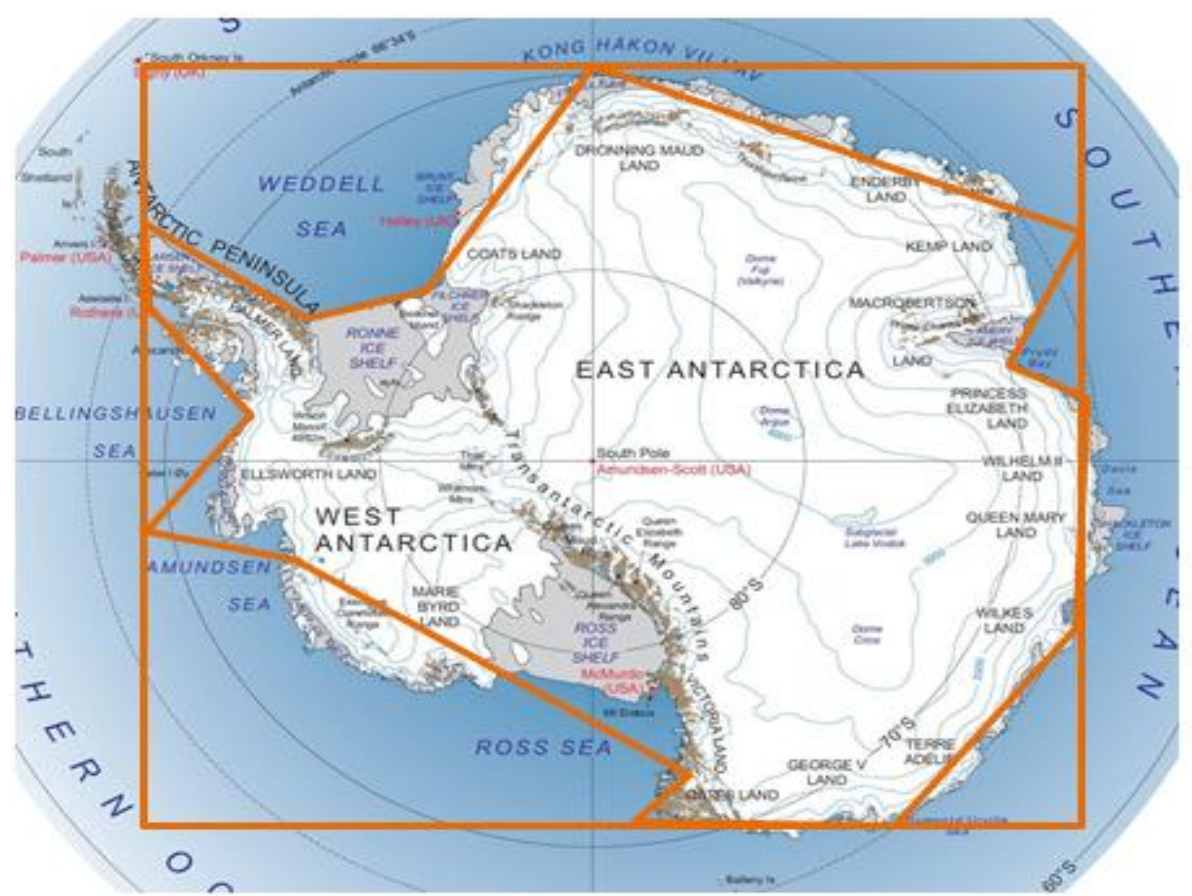

Figure 9. Estimate the area of Antarctica by polygons

\subsection{Data Collection and Data Analysis}

To collect data for this study, I gave 18 students at 9 th grade with the questionnaire to learn about their metacognitive skills in the process of learning math. The data collected from this survey will be processed using conventional statistical tools to make an assessment of the current state of using metacognitive skills of students in the process of solving math problems.

I let students to solve problems of the area of shapes, equations and linear inequalities one unknown. Before handing out experimental problematic situations to students, I assigned students to take the entrance exam with well-prepared problems. The purpose of taking the entrance exam is to find out if students have enough math knowledge and skills needed to solve problems raised in the experiment. After collecting the data in the input survey, we asked students to work with two problematic situations related to the estimation of the areas of the shapes and solving equations and linear inequalities one unknown. 
While students address the learning tasks set out, we will observe and take note students' activities. We will use qualitative analysis to describe the metacognitive skills they have used to conduct, adapt, and evaluate the problem-solving process. We will collect data from students' assignments, and from their discussion notes. We will then use a method of coding metacognitive skills in problem solving based on the existing theoretical framework of specific metacognitive skills in problem solving presented above.

The coding of research data will be conducted on each individual student participating in the study using the keywords given in the reference theory framework. In particular, the problem-solving process of students will be coded with the key words corresponding to the steps of problem reading, exploration, implementation and confirmation. Students' metacognitive skills in problem solving will be coded with key words such as problem understanding, problem analysis, planning, exploration, implementation and confirmation. 6 students participating in this study will be coded into HS1, HS2, HS3, ... HS18. We will then evaluate the development of problem-solving ability by addressing learning tasks of students

\section{Results and Discussion}

\section{- Metacognitive activities in problem-solving process of group 1}

Problem 1: This is a problem that is not familiar to students in group 1, so they have difficulty in solving the problem.
- $\quad$ Problem reading: Students in group 1 silently read the problem and do not take time to identify the requirements that the problem poses (cognition).

- Problem understanding: The students in group 1 quickly identify the requirement of the problem, advising Mr. An to buy one of the two gardens

- Planning: The students in group 1 said that there was not enough information to give a suggestion for Mr. An to buy any land in this situation

- Exploration (cognition and metacognition): The students in group 1 think that they need more information of the problem such as the using purpose, the area of the two gardens, then they can advise Mr. An to choose which garden to buy. However, after being encouraged by the teacher to search for more information to give Mr. An more appropriate advice from the hypothesis of the problem, the students in group 1 thought about estimating the area of the two given garden. The estimation of the area of the two gardens is done by dividing the gardens into 5 parts respectively. Students then estimate the areas of the fraction in two shapes together

- Implementation: Because the students in group 1 think that there are not enough assumptions needed to fully solve the situation, they initially handle the situation as follows (fig.10).

- If Mr. An's using purpose is to dig a pond or build a house, he should buy the first garden

- If Mr. An's using purpose is to plan trees, he should buy the second garden

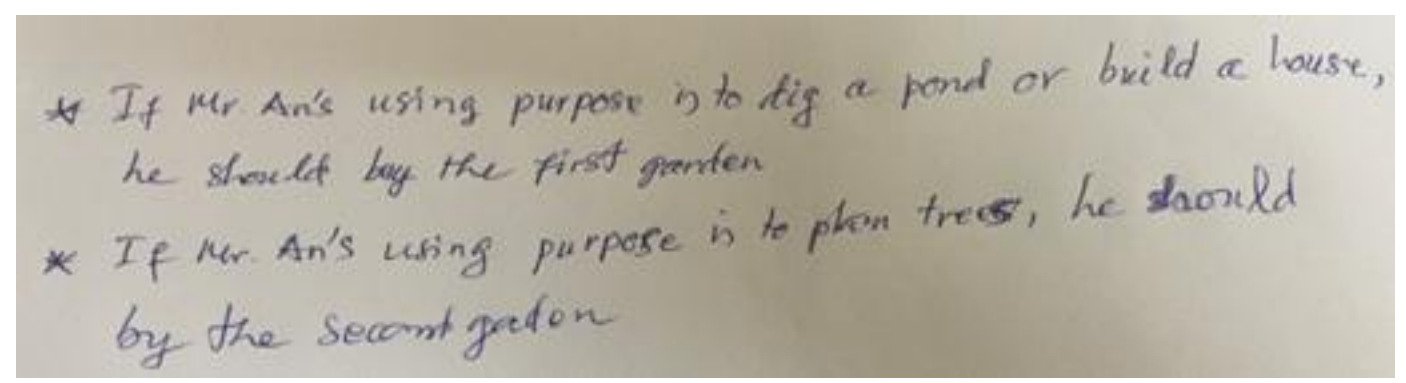

Figure 10. Suggestion of students in group 1

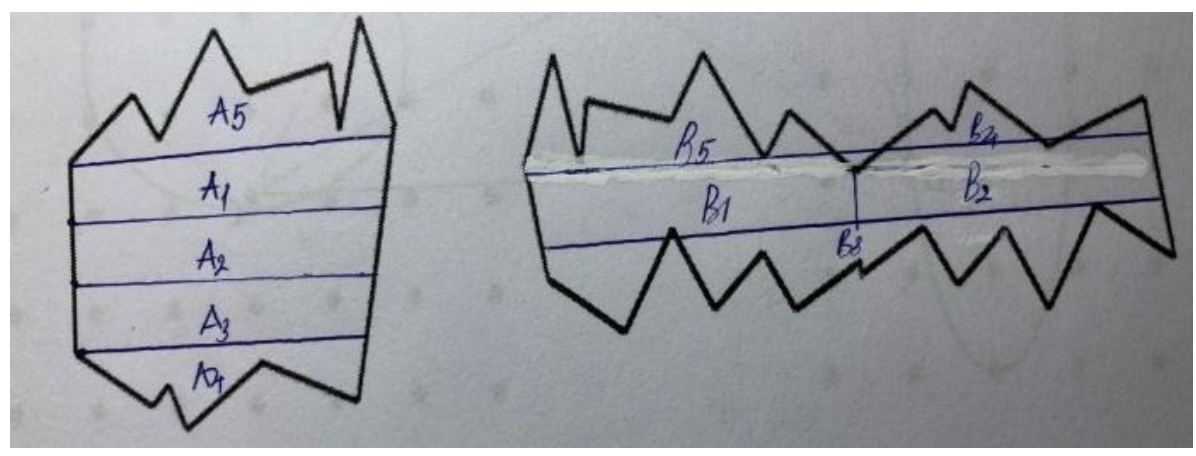

Figure 11. Estimate the area of two gardens of students in group 1 
- Confirmation: The students in group 1 fully believe in their solution because they have added assumptions to solve problems in the first situation. They also tried to estimate the area of each garden so that they could give Mr. An the most reasonable advice.

Problem 6: This is a problem that is not familiar to students in group 1, so they have difficulty in solving the problem.

- $\quad$ Problem reading: Students in group 1 silently read the problem and do not take time to identify the requirements that the problem poses (cognition).

- Problem understanding: Students in group 1 quickly identify the need of the problem to estimate the area of Antarctica.

- Planning: At first students in group 1 had difficulty in planning to find a solution to estimate the area of Antarctica. They don't know to apply what kind of knowledge to meet the requirements of the situation. They accessed internet to find out the area of Antarctica and got a figure of $14,000,000 \mathrm{~km} 2$. However, using the network to find a number only helps them to check how accurate their estimation plan is, it cannot meet the requirement of the situation at first. Then one member of the group thought about using the estimation method by breaking down the shapes as the situation they had previously met. As a result, the whole group planned to divide Antarctica into smaller sections with familiar shapes that could easily estimate the area from the knowledge and experience they had.

- Exploration (cognition and metacognition): Students in group 1 think that the Antarctic area can be estimated by breaking it down into familiar shapes. For the small areas that have been divided, they idealize them into familiar shapes such as triangles, rectangles, trapezoid ... Then they measure and calculate the area of these shapes, then adds these numbers, multiplied by the scale to estimate the area of Antarctica.

- Implementation: The students in group 1 divided Antarctica into small parts, and then they estimated the area of the small parts by idealizing them into a number of triangles, rectangles and trapezoid shapes. Then they applied the familiar area calculation formula as the following fig. 13:

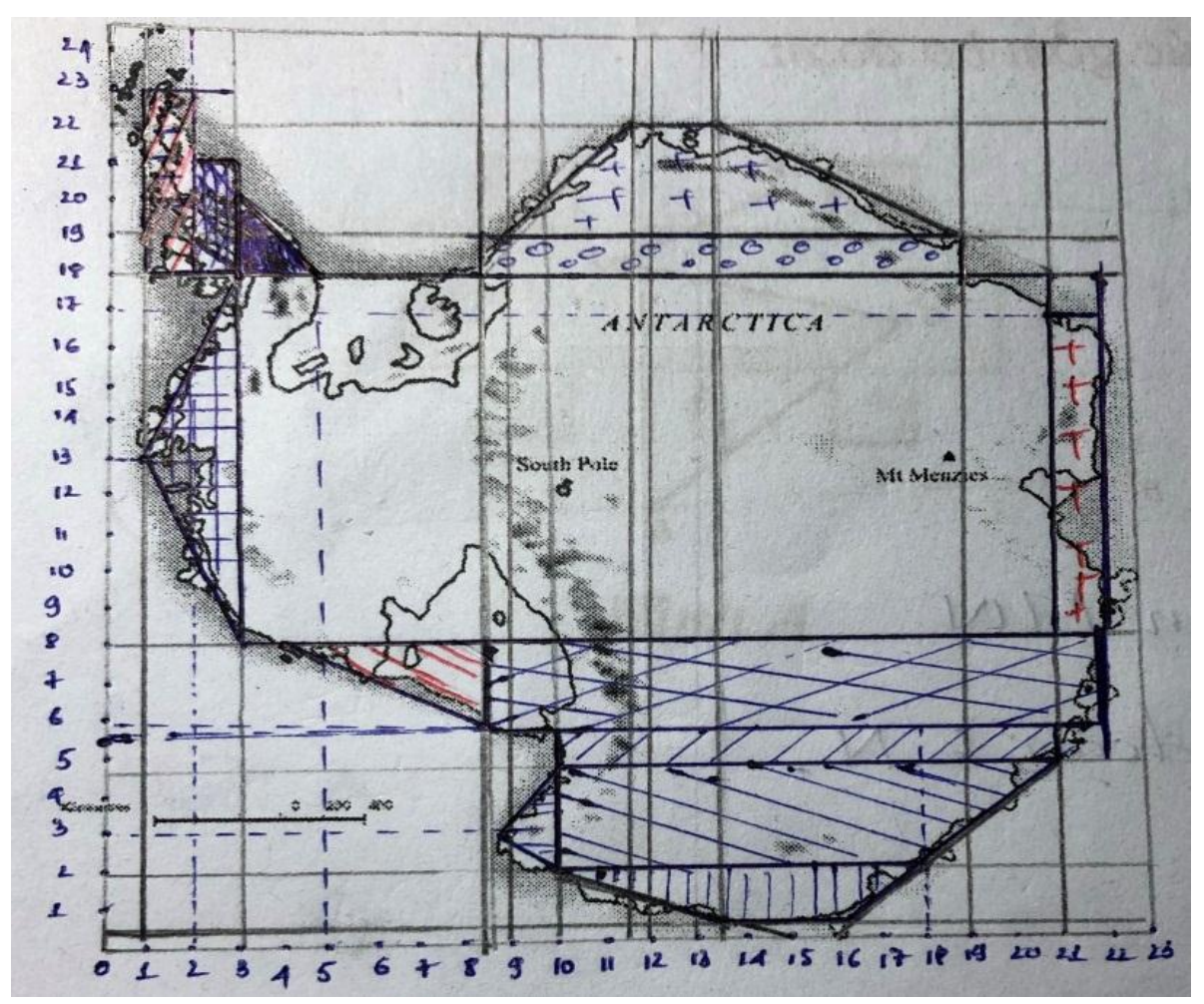

Figure 13. Group 1 students divide Antarctica into familiar shapes 


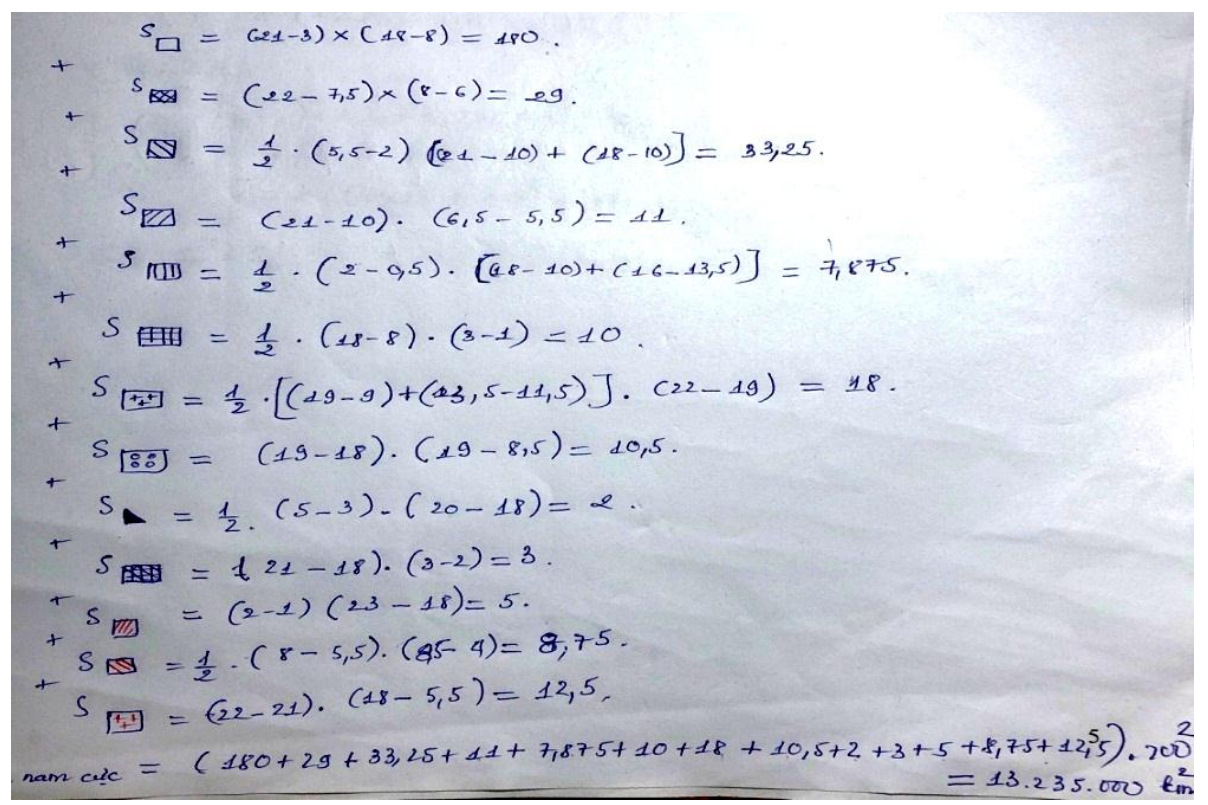

Figure 14. Estimate Antarctic acreage of group 1 students

After calculating the area of the small shapes, the students in group 1 summed them up and converted them into chains and obtained an estimate of Antarctica's area of $13,235,000 \mathrm{~km}^{2}$ as the following fig. 14 .

- Confirmation: Although they knew there would be a certain difference with the exact area of Antarctica, the students in group 1 thought that the problem-solving plan they proposed would somehow help Hong estimate the area of Antarctica in this case. The students in group 1 explain the area difference compared to the fact that they have idealized the subdivisions into familiar shapes and because the measurement and conversion of the chain ratio is still wrong. Those things have affected the results of their estimation in this situation.

\section{- Metacognitive activities in problem solving process of group 2}

Problem 1: This is an unfamiliar problem for students in group 2, so at first, they had difficulty in solving the problem:

- $\quad$ Problem reading: Students in group 2 silently read the problem and do not take time to identify the requirements raised by the problem (cognition).

- Problem understanding: The students in group 2 quickly identified the requirement of the problem, advising Mr. An to buy one of the two gardens.

- Planning: Students in group 2 have further hypothesized using a garden to grow trees. Therefore, at first, they tried to explain which garden was suitable for planting purposes. They only cared about the size and shape of the garden, not their area. After that, they thought about comparing their area and making recommendations on which garden to choose for other purposes of use.

- $\quad$ Exploration (cognition \& metacognition): Students in group 2 have added information to the problem of garden use. From there, they decided to choose the first garden because of its balanced shape and they thought it was suitable for planting. However, after being encouraged by the teacher to find more information to give Mr. An more appropriate advice from the hypothesis of the problem, the students in group 2 came to estimate the area of the two gardens. The estimation of the area of the first garden is done by using GSP software to calculate the polygon area available in this software. The students then compared the area of the two gardens by making regular estimates according to the pattern and making their own decisions.

- Implementation: Because at first students in group 2 thought they were going to use the garden to plant trees, they noticed their size. Therefore, they made the following argument to handle the situation (fig. 15).

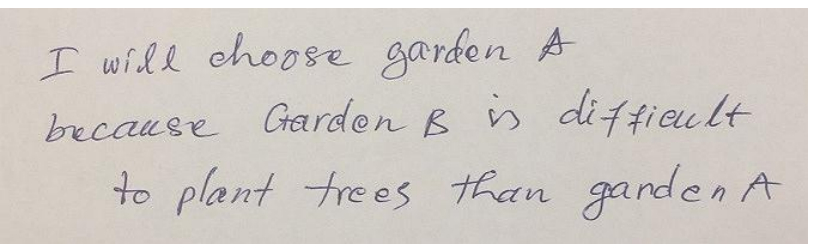

Figure 15. Suggestion to buy a garder of group 2

Some students in group 2 then thought about estimating the area of the two gardens. They used the familiar method of dividing each large shape into constituents, then comparing the area of the respective constituents (fig. 16). 


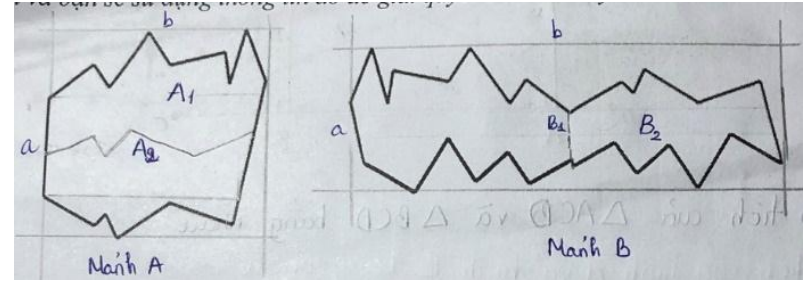

Figure 16. Estimate the area of the gardens of group 2

- Confirmation: The students in group 2 are quite confident with the problem-solving solution they proposed because they have added assumptions to solve the problem posed in the original situation. They also tried to estimate the area of each garden by using useful tools in the GSP software as well as estimating by dividing the shapes into the familiar shapes to give Mr. An an the most reasonable advice.

Problem 2: This is a problem that is not familiar to students in group 2 so they have difficulty in solving the problem:

- Problem reading: students in group 2 read the problem silently and do not take time to identify the requirements raised by the problem (cognition).

- Problem understanding: Students in group 2 quickly identified the need for the problem to estimate the area of Antarctica

- Planning: Students in group 2 accesseed internet to find out the area of Antarctica and earned a figure of $14,000,000 \mathrm{~km}^{2}$. They then used the GSP software to estimate the area of Antarctica. From the parameters obtained, they use the estimation method by breaking down the picture. As a result, the whole group planned to divide Antarctica into smaller sections with familiar shapes that could easily estimate the area using the knowledge and experience they had.

- Exploration (cognition \& metacognition): students in group 2 find it possible to estimate the area of Antarctica by breaking it down into familiar shapes like when they dealt with previous situations. They have idealized the small areas that have been divided into familiar shapes such as triangles, rectangles, trapezoid ... Then students in group 2 measured and calculated the area of these shapes then add their areas, multiplied by the scale to estimate the area of Antarctica.

- Implementation: At first students in group 2 used the polygon area measurement toolkit from GSP to estimate Antarctic area. The area measurement is made by approximating Antarctica by a polygon. Students in group 2 found the area of the polygon and approximated the area of Antarctica with the area of the polygon that is $\mathrm{cm}^{2}$. Then they convert units and convert them into chains that yield an area of Antarctica approximately equal to $\mathrm{S}=\frac{\mathrm{S}_{1}}{\mathrm{a}^{2}}=1,32 \cdot 10^{7} \quad \mathrm{~km}^{2}$ :

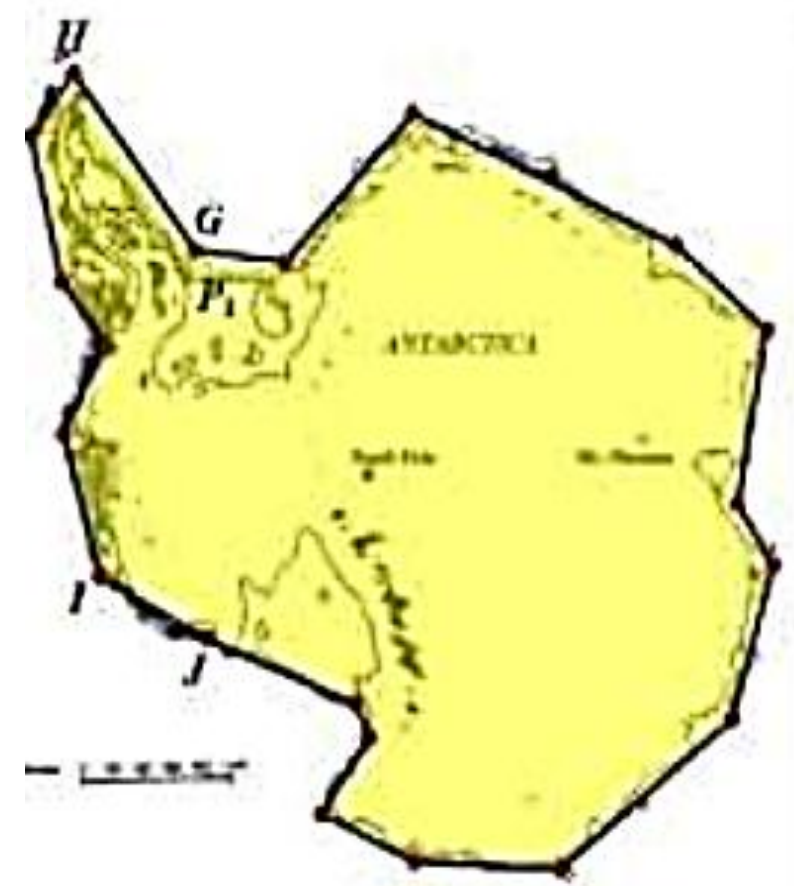

Figure 17. Estimate the area of Antarctica-Group2

After testing with GSP, the students in group 2 divided Antarctica into small parts, estimated the area of the small parts by idealizing them into a number of triangular, geometric shapes. rectangles and trapezoid, from which use the familiar area calculation formula as the following image: 


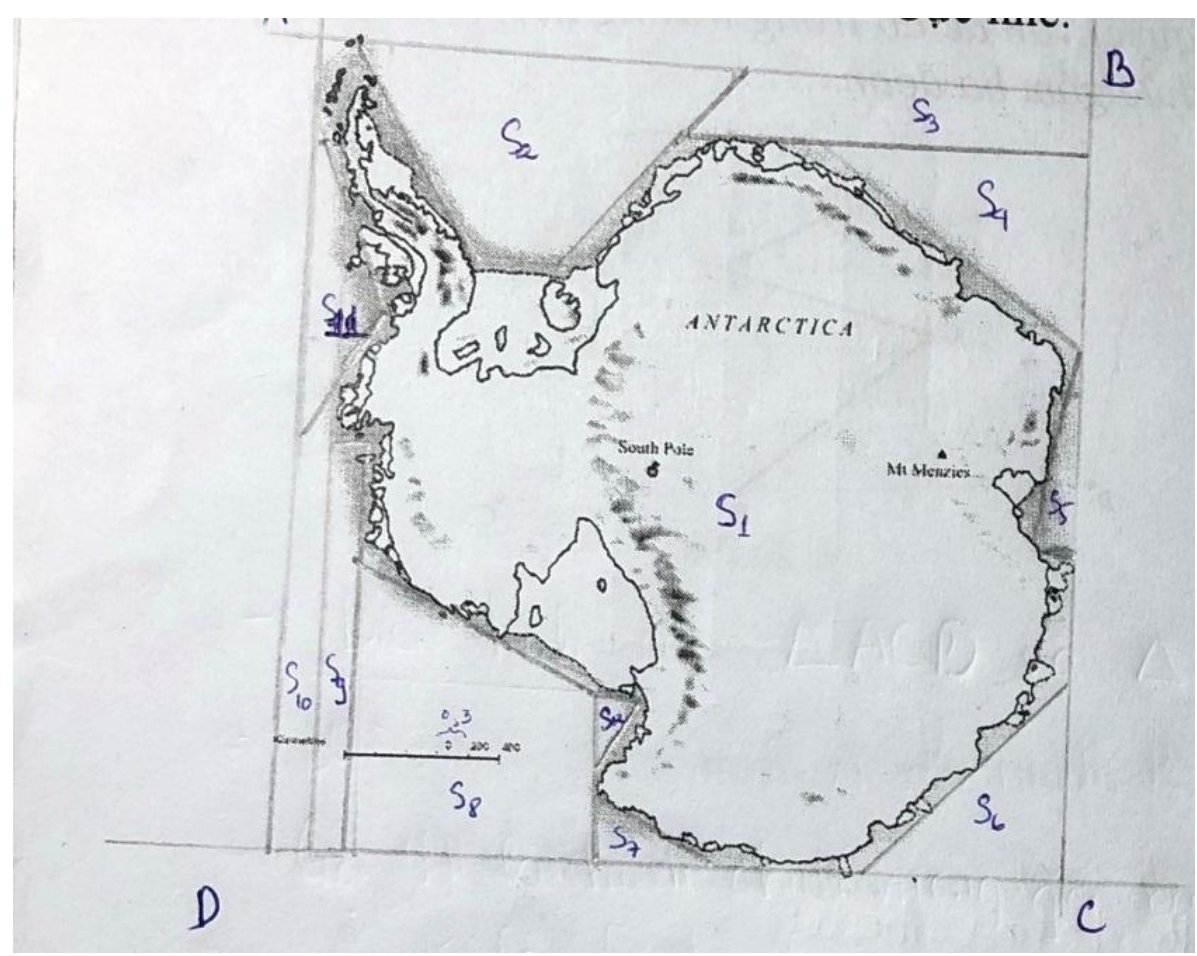

Figure 18. Divide Antarctica into familiar shapes of group 2

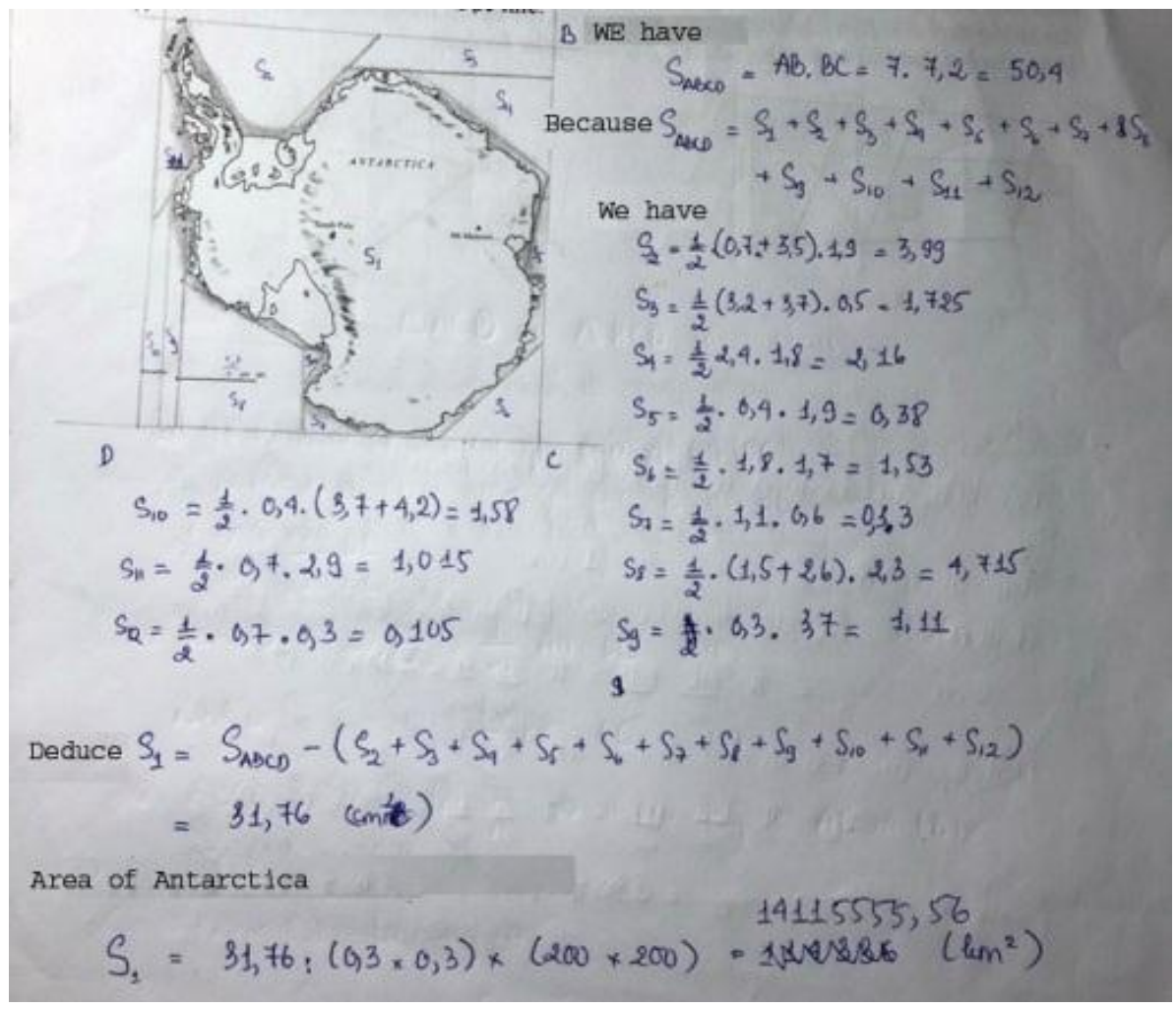

Figure 19. Estimate the area of Antarctica of group 2

After calculating the area of the shapes, the students in group 2 summed them up and converted them into chains and obtained an estimate of Antarctica's area of 13,235,000 $\mathrm{km}^{2}$ as follows (fig. 18).
- Confirmation: Although the results differed significantly with the exact area of Antarctica, the students in group 2 found that the problem-solving plan they proposed would somehow help estimate 
the area. of Antarctica in this case. The difference in area compared to the reality realized by students in group 2 is because they have idealized the subdivisions into familiar shapes and due to the measurement and conversion of the chain ratio is also certain wrong. However, they think that they has come up with an effective method when solving this problem.

\section{Findings}

In solving mathematical problems process, students reveal three groups of metacognitive skills: orientation and planning skills, monitoring and adjustment skills, and assessment skills in problem solving. Specifically, these three skill groups are shown as follows:

Orientation and planning skills in problem solving process: During problem solving, students learn data related to the problem, then give ideas and solutions. At the end they rearrange the order of ideas and solutions accordingly.

Monitoring and adjustment skills in problem solving process: students will observe and follow up the steps in problem solving process. They consider the appropriation of problem solving steps, if any step is found to be inappropriate, they will adjust and correct the problem solving process in the right direction. This skill is shown quite clearly by students during problem solving, especially when they are faced with problems in unfamiliar situations that require constant exploration, creativity, and coordination of many appropriate solutions to solve problems raised in the original situation. At such times, students must conduct a process of exploration, implementation and validation. Metacognitive skills will therefore guide the problem-solving process, support the learner in the right direction and successfully solve the problem.

Assessment skills in problem solving process: When participating in the problem solving process, students always pay attention to assessing the results achieved at the end of the problem solving process, drawing out the lessons for themselves to study math effectively in the future. It is the assessment skills in the problem-solving process that help students know the correctness of each step of the problem-solving process which will be the basis for the next step or return to previous step. This helps the student's problem solving process be effective and meet the initial requirements. In addition to assessing the outcome of the cognitive process, taking into account the reasonableness and optimism in problem-solving options, assessment skills also help learners to identify progress in terms of problem solving methods.

Although the three skill groups are clearly visible during students' problem-solving activities, the research results show that the monitoring and adjustment skills along with assessment and self-assessment skills have been shown most clearly in students' problem solving process. In particular, the assessment skills when solving problem are paid attention to by students to create the link between the hypothesis and the conclusions of the problem, from the assessment process the students will choosse the most optimal problem-solving plan for an unfamiliar situation.

Results from this study show that when students conduct problem-solving processes under the direction of metacognitive skills, they regularly conduct exploration activities to examine and assess themselves whether they are going in the right direction? From there, they will decide to continue or change their approach and solve the problem. As a result, they gradually find solutions to problems they are not familiar with at the beginning. This shows that when students are learning in an environment guided by planning, monitoring, and reflection, their ability to solve problems gradually improves. They overcome the initial difficulties and obstacles, gradually finding ways to solve the problems. Especially, when studying math in an environment with integrated GSP dynamic geometry software, the students' metacognitive skills will be more clearly revealed. These skills are regularly applied by students in the planning, exploration, implementation and validation processes. Since then they have successfully solved the problem posed in situations that were not familiar at first.

\section{Conclusions}

One of the goals of education in Vietnam is to teach students to think, including metacognitive thinking. There are several ways to promote and develop students' metacognitive thinking. Research on metacognition in general and metacognition in student problem solving is a new research direction in Vietnam in recent years. This study only explores the role of metacognition in developing problem-solving ability for secondary school students when they solve less familiar problems in math classes. If possible, further studies can be conducted to understand the impact of metacognition on students' mathematical performance as well as their mathematical ability.

\section{REFERENCES}

[1] Anderson, N. J. The Role of Metacognition in Second Language Teaching and Learning. ERIC Digest. 2002.

[2] Artzt, A. F., Armour-Thomas, E. Development of a cognitive-metacognitive framework for protocol analysis of mathematical problem solving. Cognition and Instruction, 9(2), 137-175. 1992. http://dx.doi.org/10.1207/s1532690xc i0902_3

[3] Baker, L., \& Brown, A. L. Metacognitive skills and reading. 
In P. D. Pearson, R. Barr, M. L. Kamil, \& P. Mosenthal (Eds.), Handbook of reading research (pp. 353-394). New York: Longman. 1984.

[4] Beyer, B. K.. Developing a Thinking Skills Program: A Complete Practical Plan for Developing and Implementing a Systematic Thinking Skills Program in any School. 1988.

[5] Brown, A. L. Knowing when, where, and how to remember; a problem of metacognition. Advances in instructional psychology, 1. 1978.

[6] Brophy, J. Teaching and learning mathematics: Where research should be going. Journal for Research in Mathematics Education, 323-346. 1986.

[7] Brown, A. L. Metacognition, executive control, self-regulation, and other mysterious mechanisms. In F. K. Weinert, R. (Ed.), Metacognition, Motivation, and Understanding. New Jersey: Lawrence Erlbaum. 1987.

[8] Campione, J. C., Brown, A. L., \& Connell, M. L. Metacognition: On the importance of knowing what you are doing. Research agenda for mathematics education: Teaching and assessment of mathematical problem solving. Hillsdale, NJ: Lawrence Erlbaum. 1988.

[9] Davidson, J. E., \& Sternberg, R. J. Smart problem solving: How metacognition helps. In Metacognition in educational theory and practice (pp. 61-82). Routledge. 1998.

[10] Desoete, A., \& Veenman, M. Metacognition in mathematics: Critical issues on nature, theory, assessment and treatment. In Metacognition in mathematics education. pp. 1-10. 2006.

[11] Flavell, J. H. Metacognition and cognitive monitoring. A new area of cognitive-developmental inquiry. American Psychologist, 34, 906-911. 1979.

[12] Flavell, J. H. Metacognition and cognitive monitoring: A new area of cognitive-developmental inquiry. American Psychologist, 34. 1979.

[13] Flavell, J. H. Metacognitive aspects of problem solving,. In L. B. Resnick (Ed), The Nature of Intelligence (pp. 231-235). New Jersey: Lawrence Erlbaum. 1976.

[14] Garofalo, J., Lester, F. K. Metacognition, cognitive monitoring, and mathematical performance. Journal for Research in Mathematics Education,16. 1985.

[15] Goos, M., Galbraith, P. Do it this way! Metacognitive strategies in collaborative mathematical problem solving. Educational Studies in Mathematics, 30. 1996.

[16] Gregory Schraw, David Moshman, Metacognitive theories. Educational Psychology Review, 1995, Volume 7, Number 4, Page 351, 1995. doi.org/10.1007/BF02212307

[17] Hwa Tee Yong and Lau Ngee Kiong. Metacognitive Aspect of mathematics Problem Solving. MARA University of Technology Malaysia. 2012.

[18] Kramarski, B. Promoting teachers' algebraic reasoning and self-regulation with metacognitive guidance. Metacognition and Learning, 3(2), 83-99. 2008.

[19] Kuhn, D. Metacognitive Development. Current Directions in Psychological Science, 9(5), 178-181. 2000. https://doi.org/10.1111/1467-8721.00088
[20] Kuzle, A. Preservice teachers' patterns of metacognitive behavior during mathematics problem solving in a dynamic geometry environment (Doctoral dissertation, University of Georgia), 2011.

[21] Lester Jr, F. K. The Role of Metacognition in Mathematical Problem Solving: A Study of Two Grade Seven Classes. Final Report. 1989.

[22] Lester, F. K. Building bridges between psychological and mathematics education research on problem solving. In F. K. Lester \& J. Garofalo (Eds.), Mathematical problem solving (pp. 55-85). Philadelphia: The Franklin Institute Press. 1982.

[23] Michael J. Lawson and Mohan Chinnappan. Generative Activity During Geometry Problem Solving: Comparison of the Performance of High-Achieving and Low-Achieving High School Students. Cognition and Instruction, Vol. 12, No. 1, pp. 61-93, 1994. Doi: 10.1207/s1532690xci1201_3

[24] Metcalfe, J., \& Shimamura, A. P. Metacognition: Knowing about Knowing. Cambridge, Mass: MIT Press. 1994.

[25] RW Hollingworth, C McLoughlin, Developing science students' metacognitive problem solving skills online. The Australasian Journal of Educational Technology. Vol 17, No 1, 2001. DOI: https://doi.org/10.14742/ajet.1772

[26] Schoenfeld, A. H. Learning to think mathematically: Problem solving, metacognition, and sense making in mathematics. Handbook of research on mathematics teaching and learning, 334370. 1992.

[27] Silver, E. A. Knowledge organization and mathematical problem solving. Mathematical problem solving: Issues in research, 15-25. 1982.

[28] Verschaffel, L.. Realistic mathematical modelling and problem solving in the upper elementary school: Analysis and improvement. Teaching and learning thinking skills. Contexts of learning, 215-240. 1999.

[29] Wilson, Jeni \& Clarke, David. Towards the modeling of mathematical metacognition. Mathematics Education Research Journal. 16. 25-48. 2004. Doi: 10.1007/BF03217394.

[30] Victor, A.M. The effects of metacognitive instruction on the planning and academic achievement of first and second grade children. (Doctoral Thesis). Chicago, IL: Graduate College of the Illinois Istitute of Technology. 2004.

[31] Artigue, Michèle. Learning Mathematics in a CAS Environment: The Genesis of a Reflection about Instrumentation and the Dialectics between Technical and Conceptual Work. International Journal of Computers for Mathematical Learning. 7. 245-274. 2002. Doi:10.1023/A:1022103903080.

[32] Nguyen Huu Hau, Tran Trung Tinh and Nguyen Thuy Van (2020). Steam Education Route in Vietnam: Framework and Students' Perspective. International Journal of Psychosocial Rehabilitation, ISSN:1475-7192, UK, Volume 24, Issue 5, Pages: 258-273, DOI: 10.37200/IJPR/V24I5/PR201690

[33] Mohamad Ariffin Abu Bakar, Norulhuda Ismail , "Testing the Validity and Reliability of Metaseller Tutoring Module for the Purpose of Mathematics Learning Intervention," 
7478 Metacognitive Skills with Mathematical Problem - Solving of Secondary School Students in Vietnam - A Case Study

Universal Journal of Educational Research, Vol. 8, No. 3A, pp. 35 - 41, 2020. DOI: 10.13189/ujer.2020.081405.

[34] Mohamad Ariffin Abu Bakar, Norulhuda Ismail , "Express Students' Problem Solving Skills from Metacognitive Skills Perspective on Effective Mathematics Learning," Universal Journal of Educational Research, Vol. 8, No. 4, pp. 1404 -
1412, 2020. DOI: 10.13189/ujer.2020.080433.

[35] N.T.H. Lan, T.T. Tinh, "A Perspective of Metacognition in Solving Math Problems in Vietnam Secondary Schools", Annals. Computer Science Series. 16th Tome 2 nd, 14-20. 2018. 